\title{
HISTO-HORMONAL STUDIES OF THE EFFECT OF SIDA ACUTA ON THE TESTIS OF ADULT WISTAR RATS
}

\author{
Kebe, E. Obeten ${ }^{* 1}$, Ettah, E. Nkanu ${ }^{2}$, Gabriel U. Udo-Affah ${ }^{3}$.
}

${ }^{{ }^{1}}$ Department of Anatomy and Forensic Science, Cross River University of Technology, Okuku, Nigeria.

${ }^{2}$ Department of Physiology, Cross River University of Technolog, Okuku, Nigeria.

${ }^{3}$ Department of Human Anatomy, University of Calabar, Calabar.

\section{ABSTRACT}

\begin{abstract}
This study was carried out to evaluate the effects of ethanolic leaf extract of Sida acuta on the histology of the testis and reproductive hormones of male adult Wistar rats. Twenty five rats weighing between $180-220 \mathrm{~g}$ were assigned to five groups (control, olive oil control, low dose, medium dose and high dose) with five animals each. Normal control fed only on rat chow, olive oil control group received $0.5 \mathrm{ml}$ of olive oil. The experimental groups, low dose, medium dose and high dose received $500 \mathrm{mg} / \mathrm{kgBW}, 1000 \mathrm{mg} / \mathrm{kgBW} 1500 \mathrm{mg} / \mathrm{kgBW}$ of the extract orally for 60 days respectively. The animals were sacrificed at end of sixty days using chloroform anesthesia. Blood was collected from the left ventricle of the heart through cardiac puncture for hormonal assay. The testes were dissected, sectioned for hematoxylin and eosin (H\&E). Hormonal studies showed dose dependent significant $(p<0.05)$ increase in Luteinizing Hormone $(\mathrm{LH})$ across all the treatment groups when compared to the normal and olive oil control groups. Follicle Stimulating Hormone (FSH) was reduced in the low and medium dose animals that received $500 \mathrm{mg} / \mathrm{kgBw}$ and $1000 \mathrm{mg} / \mathrm{kgBw}$ of the extract respectively when compared to the control groups, while the high dose group that received $1500 \mathrm{mg} / \mathrm{kgBw}$ of the extract showed increased FSH level. Testosterone level remained insignificant among all experimental groups when compared to the normal and olive oil control groups. Histological observations of the testes showed dose dependent distortion of the normal cytoarchitecture of the organs, as the high dose $(1500 \mathrm{mg} / \mathrm{kgBw})$ treated group revealed prominent distortion. Hence the study suggests that consumption of Sida acuta at high dose may cause adverse effect on reproductive parameters and organs.
\end{abstract}

KEY WORDS: Sida acuta, Luteinizing Hormone, Follicle Stimulating Hormone, Testosterone.

Address for Correspondence: Kebe E. Obeten, Department of Anatomy and Forensic Science, Cross River University of Technology, Okuku, Nigeria. Phone: +2348035505856

E-Mail: fredobeten@yahoo.com

Access this Article online

Quick Response code

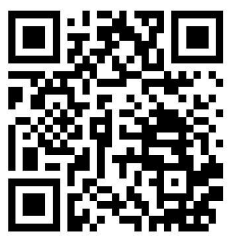

DOI: $10.16965 /$ ijar.2019.133
Journal Information

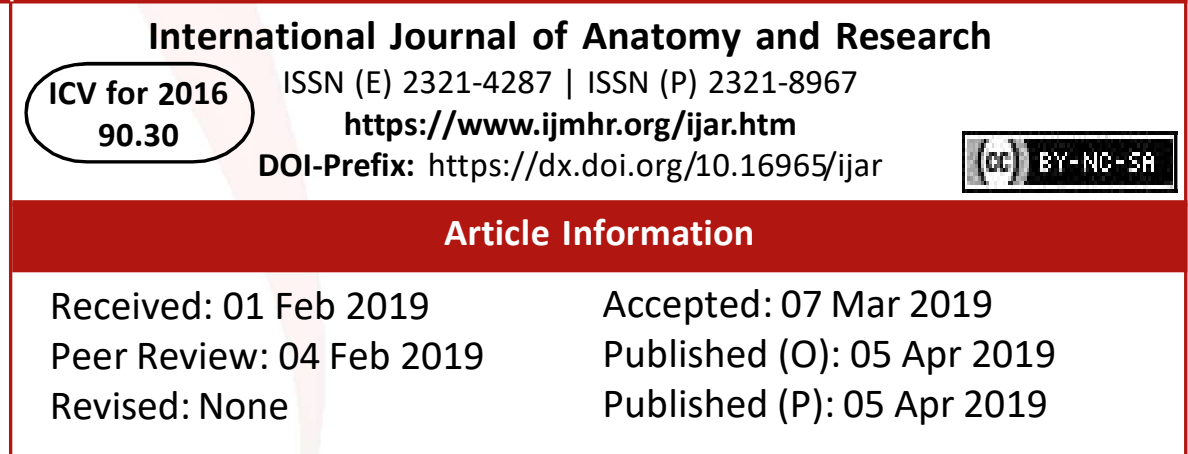

\section{INTRODUCTION}

The use of plants as medicine predates written human history. Many of the herbs and spices used by humans to season food also yield useful medicinal compounds [1,2]. Knowledge has been built for decades on the use of herbal medicinal products and extracts in the treatment of human diseases [3]. Plants are the basic source of knowledge of modern medicine. The burgeoning worldwide interests in medicinal plants reflect recognition of the validity of many traditional claims regarding the value of natural products in health care [4].

In Africa and in most of the developing countries, plants' properties are empirically appreciated. The adverse effects of chemical drugs, 
their increasing costs and greater public access to information on traditional medicine have also led to an increased interest in alternative treatments. The reason is that traditional medicine is a medicine of proximity, less constraining and non-expensive [5]. The importance of herbs in the management of human ailments cannot be overemphasized. It is clear that the plant kingdom harbours an inexhaustible source of active ingredients invaluable in the management of many intractable diseases [6]. Traditional medicines are practiced by about $60 \%$ of the world population in both developing and developed countries where modern medicines are predominantly used while an estimated $60-80 \%$ Africa's population depends solely on herbal remedies for its primary health care needs [7].

Amongst the plants used in traditional medicine is Sida acuta (Malvaceae) a shrub indigenous to pan tropical areas and widely used in traditional medicine. The genus Sida belongs to family Malvacea. The plants are mostly weeds which are observed roadside, coastal areas, forests and fields. Sida acuta is a very common weed which is also useful in Ayurveda. It is used in the treatment of malaria, diarrhea, asthma, headache, cold, fever, skin diseases and facial paralysis [8]. Sida acuta (Malvaceae) is an erect perennial shrub found throughout the hotter parts of India and Nelpal. It is used for various medicinal purposes such as liver disorders, diuretic and abortifacient in ayurvedic preparations, asthma, fever, headache (migraine), cough, cold, ulcer, antihelminthic, snake bite, urinary diseases, female disorders, antifertility agent and sedative. The aerial part of the plant is the most frequently used part [6].

Increased awareness of the significance of medicinal plants and nutrition to the health of individuals and communities has necessitated the need for knowledge of the food nutrients and phytochemicals presents in the various parts of different plants. The phytochemicals contained in the plants are largely responsible for the definite physiological activity they exert on human body and their nutritional value is determined by the food nutrient they contain [9]. The testes are productive organs in male which develop in relation to the lumber region of the posterior abdominal wall. During fetal life they gradually descend to the scrotum. They reach the iliac fossa during the 3rd month and at the site of the deep inguinal ring to the 7th month of intrauterine life. They pass through the inguinal canal during the 7th month and are normally in the scrotum by the end of the 8 th month [10].

The testis is subdivided into approximately 250 lobules by septal extensions from the tunica albuginea. Each lobule contains 1 to 4 seminiferous tubules embedded in a stroma of "loose interstitial connective tissue which contains blood and lymphatic vessels and macrophages, but lacks typical fibroblast and other loose connective tissue cells. Seminiferous tubules fill most of the volume in the testis. It is lined with a complex stratified epithelium; it is about 150$250 \mathrm{~cm}$ in diameter and $30-70 \mathrm{~cm}$ long. The seminiferous tubules narrow to form the straight tubule or tubule recti that connect the seminiferous tubule to anastomosing rete testis [11]. The seminiferous tubule consists of tunics of fibrous connective tissue, a well-defined basal lamina and a complex germinal and seminiferous epithelium. The Fibrous tunica propria enveloping the seminiferous tubule consist a several layer of fibroblast.

\section{MATERIALS AND METHODS}

Extract preparation: Fresh Sida acuta leaves was harvested from farms in Ugep, Yakuur Local Government Area of Cross River State and taken to the herbarium unit of the University of Calabar, Calabar for proper identification and authentication. The leaves were washed with water to remove debris and sand, air dried and grounded into powder using a table grinder and kept in air tight containers under dry conditions.

Modified method of [12] was used for extraction. Two hundred grams of grounded Sida acuta leave was macerated in $1000 \mathrm{ml}$ absolute ethanol for 72 hours properly covered and labeled. The extract was then be filtered with sterile filter paper (Watman No. 1). The filtrate was evaporated to dryness at $40^{\circ} \mathrm{C}$ in a vacuum using a rotator evaporator and stored at $50^{\circ} \mathrm{C}$ in a refrigerator until required for use. Approximate concentration of the extract was dissolved in $10 \mathrm{ml}$ of olive oil. The olive oil was used as a vehicle. 
Experimental animals: The study constituted a total of twenty five male Wistar rats (8-10 weeks old, weighing180 -220 g) which was obtained from the Department of Pharmacology, University of Calabar, Calabar. The rats were housed in wire-wooden cages under controlled light schedule (12-hours light and 12-hours dark cycle) and were fed standard rat chow and water ad libitum. The animals were allowed to acclimatize for 2 weeks before the start of the administration.

Experimental design:The rats were randomly divided into 5 groups each containing 5 rats. Control group was fed with standard rat chow and water ad libitum without any administration of the extract. Olive oil control group received $0.5 \mathrm{ml}$ of olive oil throughout the duration of the experiment. The low dose group received $500 \mathrm{mg} / \mathrm{kgBw}$, medium dose group received $1000 \mathrm{mg} / \mathrm{kgBw}$ while the high dose group received $1500 \mathrm{mg} / \mathrm{kgBw}$ of the ethanolic extract of Sida acuta orally by means of orogastric tube daily, for 60 days respectively

Termination of experiment: At the end of treatments, the animals were sacrificed under chloroform anesthesia. Blood was collected from the left ventricle of the heart and stored in heparinized bottles for hormonal assay. Testes were dissected out and fixed in Bouins fluid for 24 hours for routine histological study.

Histological studies: The testes of the rats were removed under chloroform anaesthesia, preserved in $10 \%$ formal saline for 48 hours and then dehydrated through ascending grades of alcohol, 2 changes of $70 \%, 90 \%, 95 \%$ and absolute alcohol for one hour in each change. After dehydration the tissue were cleared in xylene, 3 changes, 1 hour in each. The tissues were placed in two 2 changes of paraffin wax for 20 minutes each for paraffin wax impregnation in an oven at 57 degree Celsius. They were embedded in molten paraffin wax inside the $L$ shaped Leuckhart mould. The blocks were trimmed and mounted on wooden blocks. Serial sections were cut using a rotatory microtome at 5 thickness. Sections were floated in a water bath to spread out and later picked on albuminised slides and dried on a hot plate at 52 degree celcius. To stain, slides were put in staining racks and placed in staining wells containing xylene to dewax, then they were rehydrated in descending grades of alcohol, absolute alcohol ( 2 changes), $70 \%$ alcohol and then water for 5 minutes after which they were stained with haematoxylin for 5 minute. Excess haematoxylin was washed off with water and differentiated with $1 \%$ acid alcohol. Sections were counter stained with $1 \%$ eosin and washed off with water. They were dehydrated with $70 \%$, $90 \%$ and absolute alcohol and finally cleared in xylene to remove water. A drop of mountant was placed on the surface of the slides and covered with a 22 by $22 \mathrm{~mm}$ cover slip and observed under a light microscope.

\section{Hormonal analysis}

Estimation of Serum LH: The serum LH was estimated using Dialab Kit (Austria) for ELISA for quantitative determination of FSH in the serum.

Principle: The ELISA test for LH was performed as an indirect solid phase sandwich-type immunoassay. Microwells are coated with nti-monoclonal FSH followed by blocking the unreacted sites to reduce non-specific binding. Four steps were involved in this principle:

LH antigen present in the standard and sample bind to the coated antibody. The anti gen- antibody complex is reacted with enzyme (HRP) labelled antimonoclonal LH conjugate resulting in the $\mathrm{LH}$ antigen sandwiched between the solid phase antibody and the enzyme conjugate. The enzyme converts added substrate (TMB) to form a coloured solution. The intensity of colour change which is considered proportional to the concentration of antibodies present in the sample is read by ELISA machine.

\section{Test procedure}

- All kit components and samples were brought to room temperature.

- $50 \mu \mathrm{l}$ of blank, calibrators and samples were pipette into their respective wells

- $100 \mu$ l of diluted enzyme conjugate was added to the wells except for blank and incubate 60 minutes at room temperature.

- The well was wash 3 times with $200 \mu$ of distilled water.

$-100 \mu \mathrm{l}$ of substrate solution was then added to each microwell in the same order and timing as 
for enzyme conjugate. Blank well included

- It was then incubated at room temperature in the dark for 20 minutes

- $100 \mu$ l of stop solution was added to each well using the same order and timing as for addition of the substrate.

- The absorbance and concentration of the sample was read at $450 \mathrm{~nm}$ against the blank in an ELISA machine within 30 minutes of addition of the stop solution.

Estimation of serum FSH: The serum FSH was estimated using Dialab Kit (Austria) for ELISA for quantitative determination of FSH in the serum.

Principle: The ELISA test for FSH was performed as an indirect solid phase sandwich-type immunoassay. Microwells are coated with anti-monoclonal FSH followed by blocking the unreacted sites to reduce non-specific binding. Four steps were involved in this principle:

FSH antigen present in the standard and sample bind to the coated antibody. The antigen-antibody complex is reacted with enzyme (HRP) labelled antimonoclonal FSH conjugate resulting in the FSH antigen sandwiched between the solid phase antibody and the enzyme conjugate. The enzyme converts added substrate (TMB) to form a coloured solution. The intensity of colour change which is proportional to the concentration of antibodies present in the sample is read by ELISA machine.

\section{Test procedure}

- All kit components and samples were brought to room temperature

- $50 \mu$ of blank, calibrators and samples were pipette into their respective wells

- $100 \mu \mathrm{l}$ of diluted enzyme conjugate was added to the wells except for blank and incubate 60 minutes at room temperature.

- The well was wash 3 times with $200 \mu$ of distilled water.

$-100 \mu \mathrm{l}$ of substrate solution was then added to each microwell in the same order and timing as for enzyme conjugate. Blank well included

- It was then incubated at room temperature in the dark for 20 minutes

- $100 \mu$ l of stop solution was added to each well using the same order and timing as for addition of the substrate.

- The absorbance and concentration of the sample was read at 450nm against the blank in an ELISA machine within 30minute of addition of stop solution.

Estimation of serum testosterone: Serum testosterone was estimated using Rapid lab kit (United Kingdom) for the enzyme linked immunosorbent assay (ELISA) for quantitative determination of testosterone.

Principle: The "EIA" -steroid testosterone is a one-step immunoassay to determine the presence of testosterone in the serum using competitive microplate enzyme immunoassay. Plates are coated with antitestosterone antibodies. Serum samples or standard is first added to microplate well. Enzyme -testosterone conjugate is then added. Testosterone present in the sample or standard competes with enzyme testosterone conjugate for binding with antitestosterone coated microplate to form an antigen-antibody complex.

Unbound conjugate was removed by washing. The enzyme activity in the antibody-bound fraction is inversely proportional to the native testosterone concentration. The enzyme activity is revealed by a color change in TMBsubstrate solution.

\section{Test Procedure}

-All reagent and sample were brought to room temperature before use.

$-25 \mu$ l of blank,appropriate calibrators and serum sample was added into the assigned well.

- $100 \mu$ l of conjugate was added to all wells

- The well was covered with a lid or protective film and incubates on a thermosaker (approximately $500-800 \mathrm{rpm}$ ) for 30 minutes at $37^{\circ} \mathrm{C}$.

- The wells were wash 5times with $300 \mu$ of working washing solution per well and tap the plate firmly against absorbent paper to ensure that it is dry.

- $100 \mu \mathrm{l}$ of TMB-substrate was then added to each well at time intervals

- The well was incubated again for 25 minutes at room temperature in the dark.

$-150 \mu$ l of stopping reagents was then added to 
each well at the same time interval. It was gently mixed for 10 seconds.

- Absorbance was read on an ELISA Reader at $450 \mathrm{~nm}$ within 20 minutes after stopping the reaction.

\section{RESULTS}

\section{Hormonal studies}

Luteinizing Hormone (LH): There was no significant difference in the luteinizing hormone level across the entire experimental groups when compared to the normal control. However, the low dose group showed a significant $(p<0.01)$ increase $(8.18+0.37)$ when compared to olive oil control group $(5.87 \pm 0.46)$. The medium and high dose group were significantly increased $(p<0.001)(10.86 \pm 0.19$ and $10.25 \pm 0.19)$ respectively, when compared to the olive oil control group. There was significant $(p<0.001)$ increase $(10.86 \pm 0.19)$ and $(p<0.01)(10.25 \pm 0.33)$ in luteinizing hormone levels in the medium and high dose groups respectively when compared to the low dose group (8.18+0.37) (Figure 1).

Follicle Stimulating Hormone (FSH): The follicle stimulating hormone levels in the normal control and oil control were both statistically insignificant. The low dose group was significantly $(p<0.001)$ lower $(0.95 \pm 0.07)$ compared to the control group $(2.65+0.24)$. This group was also significantly $(p<0.001)$ lower compared to the olive oil control group (2.91+0.24).

The medium dose group was significantly $(p<0.05)$ lower $(1.83 \pm 0.21)$ when compared to the normal control and also significantly lower $(p<0.001)$ compared to olive oil control group. Comparing the medium dose with the low dose group, there was significant $(p<0.01)$ increase in the medium dose group. The high dose group showed insignificant difference compared to the normal control and olive oil control groups. This group however, was significantly higher $(2.70 \pm 0.19)$ at $(p<0.001)$ and $(p<0.05)$ compared to the low and medium dose groups respectively (Figure 1).

Testosterone: The testosterone level remained insignificant among all experimental groups when compared to the normal and olive oil control groups. Among groups treated with Sida acuta extract, the medium dose was significantly $(p<0.01)$ decreased $(0.79 \pm 0.04)$ compared to the low dose group (1.18+0.07) (Figure 2).

Fig. 1: Result of Follicle stimulating hormone and Luteinizing hormone in experimental animals.

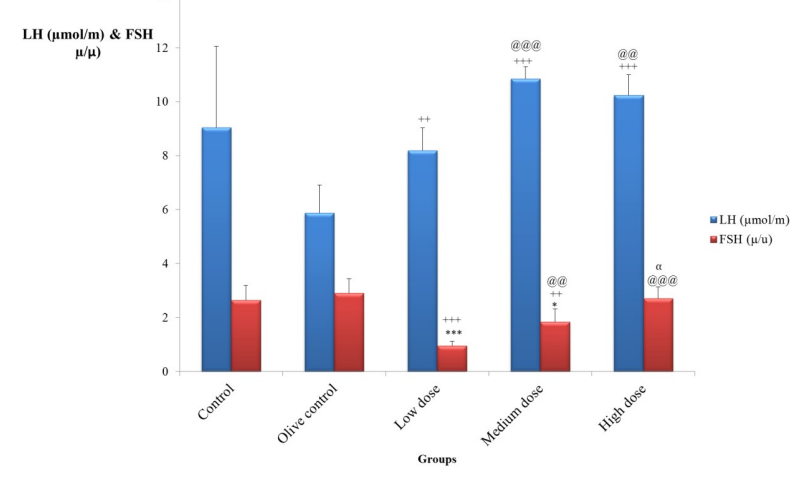

* Significantly different compared to normal control at $\mathrm{p}<0.05$

*** Significantly different compared to normal control at $\mathrm{p}<0.001$

++ Significantly different from olive oil control at $p<0.01$ +++ Significantly different from olive oil control at $p<0.001$

@@Significantly different from low dose group at $\mathrm{p}<0.01$

@@@ Significantly different from low dose group at $\mathrm{p}<0.001$

z\# Significantly different between medium and high dose group at $p<0.05$

Fig. 2: Result of Testosterone hormone in experimental animals.

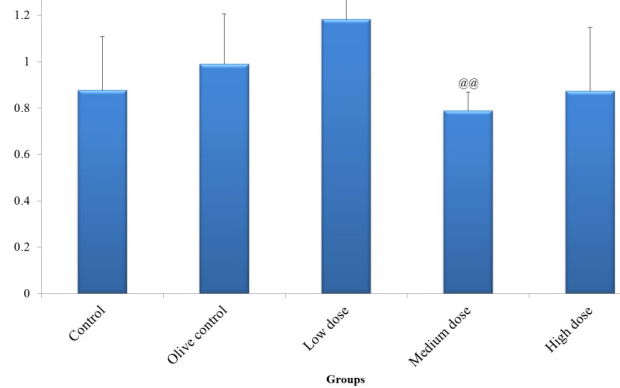

@@Significantly different from low dose group at $\mathrm{p}<0.01$

Histological observations: Histological study of the testis in the control group using haematoxylin and eosin staining method showed normal histological features: seminiferous tubules containing sertoli cells and spermatogonia in different stages of development. The germinal centre contains sperm cells. The spaces between the tubules contain connective tissue and interstitial cells of leydig (Plate 1). 
Plate 1: Photomicrograph of testis of control group showing seminiferous tubules (ST), cells of sertoli (CS) and spermatogonia (SP) at different stages of development. Germinal center (GC) shows sperm cells. Interstitial cells of Leydig (LY) were found in the interstitial layer (IL) between tubules. No pathology seen. X400. H \& E

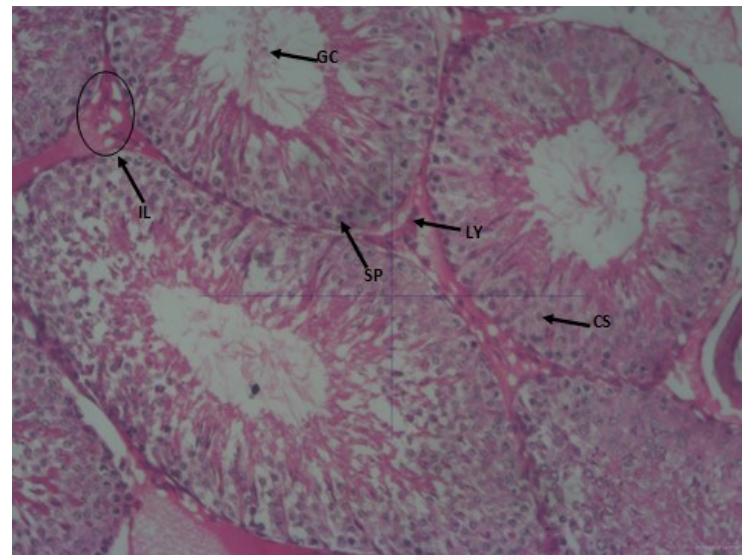

Plate 2: Photomicrograph of testis of olive oil control group showing seminiferous tubules with numerous Sertoli cells (SC) scattered at the peripheral edges of these tubules and sperm cells within the lumen (SP). Interstitial cells of Leydig (LY) and blood vessels (BV) were found in the interstitial layer (IL) between tubules. No pathology seen. :X400. H \& E.

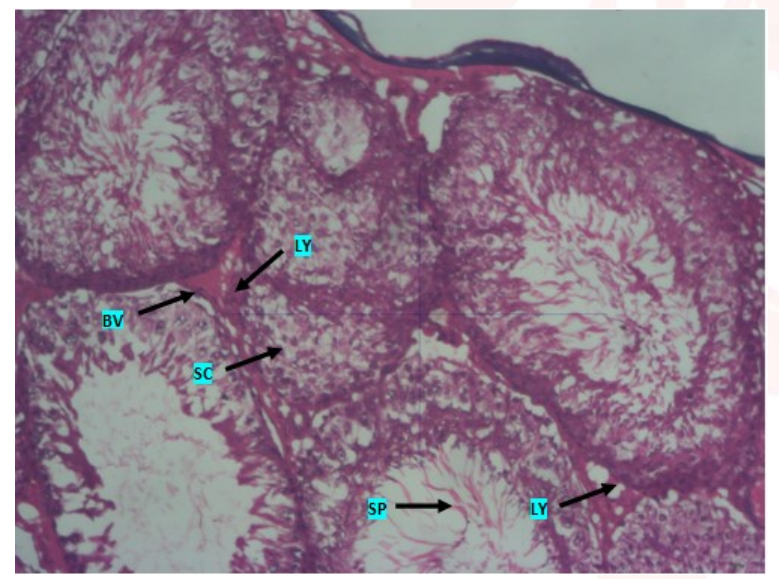

Plate 3: Photomicrograph of low dose of the testis showing seminiferous tubules. The cells of sertoli (CS) and the darker spermatogonia (S) appear normal. Germinal center (GC) of one tubule shows a light cellular granulomatous response (BLACK ARROW). Interstitial layer (IL) is also seen. No pathology seen. X400. H \& E.

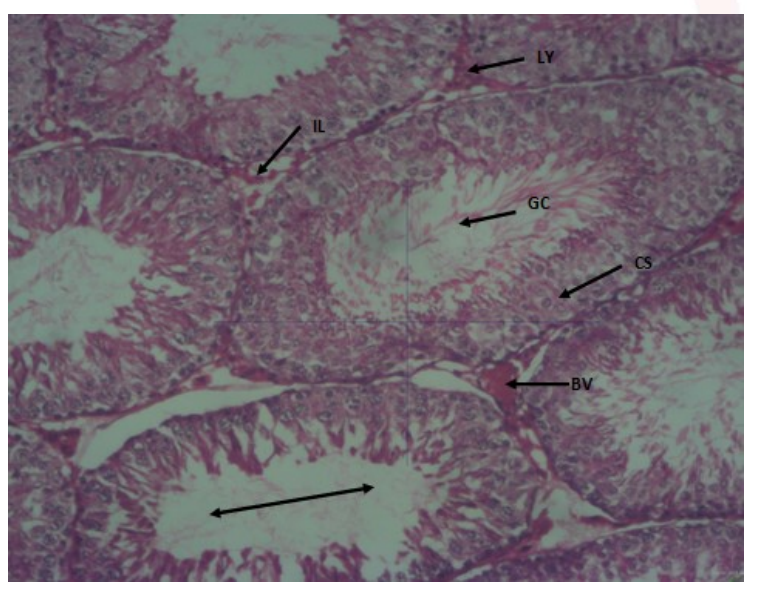

Int J Anat Res 2019, 7(2.1):6424-31. ISSN 2321-4287
Plate 4: Photomicrograph of testis of medium dose group that received $1000 \mathrm{mg} / \mathrm{kgBw}$ of Sida acuta ethanolic leaf extract showing seminiferous tubules with cells of Sertoli (CS) and darker stained spermatogonia (S). The germinal center (GC) is filled by sperm cells. No pathology seen. X400. H \& E

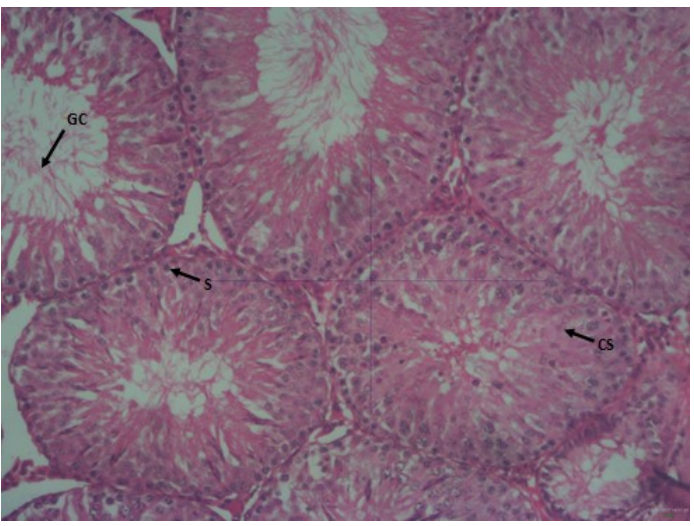

Plate 5: Photomicrograph of testis of high dose group that received $1500 \mathrm{mg} / \mathrm{kgBw}$ of Sida acuta ethanolic leaf extract showing seminiferous tubules with a spongy architecture indicating a cellular degeneration and cellular lost within the seminiferous tubules. X400. $H \& E$

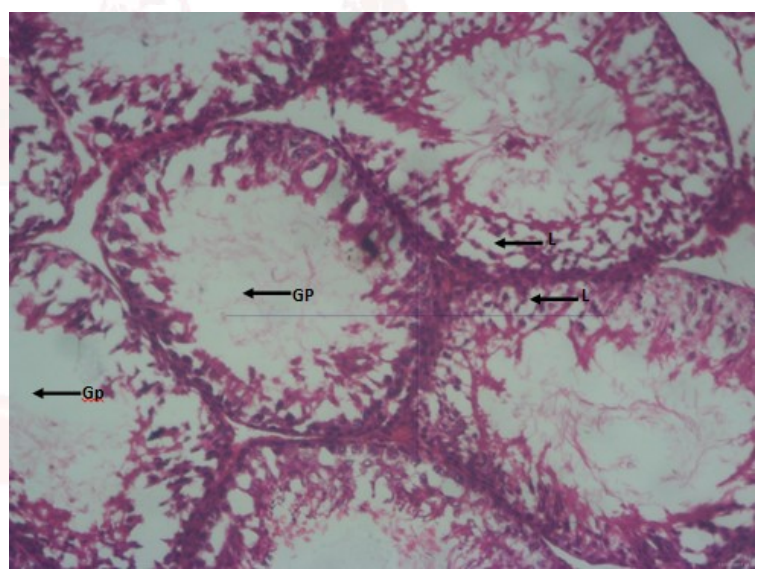

There was no pathology observed in the olive control as the testis showed seminiferous tubules with numerous sertoli cells scattered at the peripheral edges of the tubules, sperm cells are seen at the centre of the tubules. The interstitial space appeared normal and vascularized (Plate 2).

Section of a testis of animal in the low dose group that received $500 \mathrm{mg} / \mathrm{kgBw}$ of Sida acuta ethanolic leaf extract showed the seminiferous tubules, sertoli cells and spermatogonia in different stages of development. Group of leydig cells were seen in the interstitial connective tissue. The germinal centre of one of the tubules shows a light cellular granulomatous response (Plate 3).

There was no observable pathology in the medium dose group animals that received 
$1000 \mathrm{mg} / \mathrm{kgbW}$ of extract of Sida acuta. The seminiferous tubules contain normal sertoli cells and spermatoonia at different stages of development (Plate 4). Pathology was observed in sections of testis in the high dose group animals that received $1500 \mathrm{mg} / \mathrm{kgBw}$ of ethanolic leaf extract of Sida acuta. The seminiferous tubules was characterized with cellular degeneration and cellular lost (Plate 5).

\section{DISCUSSION}

In this study the serum LH level in the entire experimental animals showed no significant difference when compared to the normal control. However among the experimental groups, the low dose revealed a significant increase $(P<0.01)$ as against the olive oil control group and the medium and high dose groups exhibited a significant increase $(P<0.001)$ respectively when compared to the olive group. Significant increases $(P<0.001)$ and $(P<0.01)$ respectively was observed in the medium and high dose groups as against the low group. The result of luteinizing hormone in this study does not reveal any pathology as a lower than low levels is an indication of a disease stage which include entry disorder, hypothalamic suppressor, hypopituitarism, hyperprolactinemia. [13]. A higher level will imply a gonadal dysfunction and can be seen in a variety of disease, including but not limited to testicular failure, congenital adrenal hyperplasia [14].

The level of FSH in the normal and olive oil control were both insignificant statistically. The low dose exhibited significantly lower levels $(\mathrm{P}<0.001)$ compared to the normal and olive oil control groups respectively while the medium dose showed significantly lower levels $(P<0.05)$ and $(P<0.001)$ when compared to the normal and olive oil control groups respectively. However, when comparing the medium dose group not that of the low group there was significant increase $(P<0.01)$. The high dose group that received $1500 \mathrm{mg} / \mathrm{kgBw}$ of the extract revealed differences that are insignificant when compared to the normal and olive oil control groups.

The FSH is an essential component of the hormone system that regulates growth, development and sexual reproduction in males and hence can be used as a marker to identify and monitor certain disease states and as a therapy for other. The lower level of FSH reflected by the experimental groups may mean glands within the pituitary or hypothalamus are not working properly and hence do not produce normal amounts of some or all hormones which could lead to certain type of brain tumor of the pituitary gland and sometimes associated with vision changes [15].

Testosterone serum level in this study was insignificant in all the experimental groups when compared to the normal and olive oil control groups. This result showed that there was no pathology observed in the testosterone levels. However low testosterone has been classified with unwanted body change such as increased abdominal fat and decreased muscle mass. Unfortunately abdominal fat affects organs like the heart, liver and kidney more adversely than fat anywhere else. Low level of testosterone is associated with increased risk of cardiovascular disease and metabolic problem such as diabetes. Low testosterone could also cause erectile dysfunction, depression, and mood change and low bone density [16].

Histological observations of the testes showed dose dependent distortion of the normal cytoarchitecture of the organs, as the high dose (1500mg/kgBw) treated group revealed prominent distortion.

\section{CONCLUSION}

The results of this experimental work suing animal models may not be used to give direct application in man but it gives an insight into the possible toxic effects of the substance. From the results obtained, it is suggestive that consumption of Sida acuta at high dose may cause adverse effect on reproductive parameters and organs.

\section{Conflicts of Interests: None}

\section{REFERENCES}

[1]. Tapsell, L. C, Hemphill, I. Cobiac L. Health benefits of herbs and spices: the past, the present, the future. Medical Journal of Australia. 2006;185(4):S4-24.

[2]. Lai, P K., Roy, J. Antimicrobial and chemopreventive properties of herbs and spices. Current Medical Chemistry. 2004;11(11):1451-60. 
[3]. Iwalewa, E. O., Mcgaw, L. J., Naidoo, V. \& Eloff, J N. Inflammation: the foundation of diseases and disorders. A review of phytomedicines of South African origin used to treat pain and inflammatory conditions. African Journal of Biotechnology.2007;6:2868-2885.

[4]. Ahmed, M. \& Hussain, F. Chemical Composition and Biochemical Activity of Aloe Vera (Aloe Barbadensis Miller) Leaves. International Journal of Chemical and Biochemical Sciences. 2013;3(5):29-33.

[5]. Agunbiade, O. S., Ojezele, O. M., Ojezele, J. O. \& Ajayi, A.Y. Hypoglycaemic activity of Commelina africana and Ageratum conzyzoides in relation to their mineral composition. African Health Sciences, 2012;12(2):198 -203.

[6]. Palaksha, M. B. \& Ravishankar, K. Phytochemical Screening and Evaluation of in vitro Antibacterial and Antihelminthic Activities of Sida acuta Leaf Extracts. Journal of Chemical and Pharmaceutical Research. 2012;4(11):4757 - 4761.

[7]. Adesuyi, A. O., Awosanya, O. A., Adaramola, F. B. \& Omeonu A. I. Nutritional and Phytochemical Screening of Aloe barbadensis. Current Research Journal of Biological Sciences. 2011;4(1):4-9.

[8]. Wake, R. R. In vitro Antimicrobial Activity of Extracts of Plants of Genus Sida Linn. International Journal of Pharmaceutical Research and Development. 2012;3(11):210-214.

[9]. Tijjani, M. A., Abdurahman, F. I., Buba, S. W., Mala, G. I., Akan, J. C., Aji, B. M. \& Abdullahi A. S. Chemical and Proximate Contents of Methanolic Leaf Extract of Piliostigma thonningii schum (Camel Foot). Journal of Chemical and Pharmaceutical Research. 2012;4(5):2409-2414.
[10]. Singh, A. \& Singh, S.K. Evaluation of antifertility potential of Brahmi in male mouse. Contraception 2009;79:71-79.

[11]. Singh, S.K. \& Chakravarty, S. Histologic changes in the mouse testis after bilateral vasectomy. Asian Journal of Andrology. 2000;2:115-120.

[12]. Abdulrhman, F., Inyang, S. I., Abbah, J., Binda, L., Amos, S. \& Gamanial, K. Effect of aqueous leaf extract of Irvingia fabonesis on gastrointestinal tracts of rodents. Indian Journal of Experimental Biology. 2004;42:787-791.

[13]. Barker NM. Luteinizing Hormone Deficiency. 2010; Medscape Reference. 8/31/2010. Available at http:/ /emedicine.medscape.com/article/255046-overview.

[14].Nguyen, H. C. T. Luteinizing Hormone. 2015 Medscape. http://emedicine. medscape.com /article/ 2089268overview\#a30.

[15]. Jon. B. The Endocrine System: Hypothalamus, Pituitary and Pineal Glands. The Endocrine System, Hormones and Natural Alternatives. 2010;1:2-4.

[16].Peeyush, K., Nitish, K., Devendra, S. T. \& Ajay, P. Male hypogonadism: Symptoms and treatment. Journal of Advanced Pharmaceutical Technology and Research. 2010;1(13):297-301

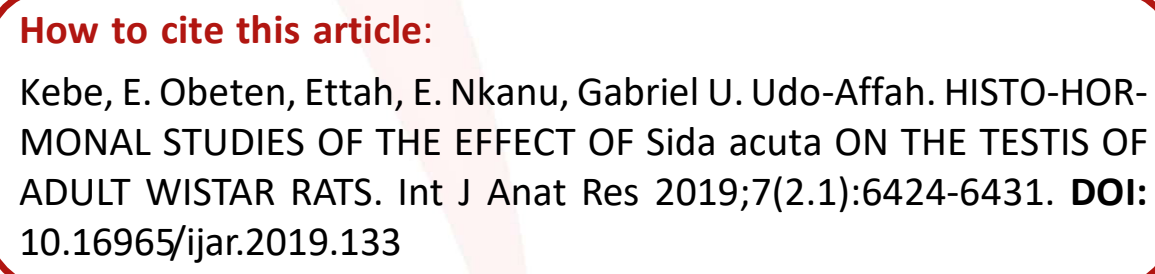

